\title{
Gaussian Filtering with Tapered Liquid Crystal Photonic Bandgap Fibers
}

\author{
Scolari, Lara; Alkeskjold, Thomas Tanggaard; Bjarklev, Anders Overgaard
}

Published in:

LEOS proceedings 2006

Link to article, DOI:

10.1109/LEOS.2006.279044

Publication date:

2006

Document Version

Publisher's PDF, also known as Version of record

Link back to DTU Orbit

Citation (APA):

Scolari, L., Alkeskjold, T. T., \& Bjarklev, A. O. (2006). Gaussian Filtering with Tapered Liquid Crystal Photonic Bandgap Fibers. In LEOS proceedings 2006 (pp. ThN3). IEEE. https://doi.org/10.1109/LEOS.2006.279044

\section{General rights}

Copyright and moral rights for the publications made accessible in the public portal are retained by the authors and/or other copyright owners and it is a condition of accessing publications that users recognise and abide by the legal requirements associated with these rights.

- Users may download and print one copy of any publication from the public portal for the purpose of private study or research.

- You may not further distribute the material or use it for any profit-making activity or commercial gain

- You may freely distribute the URL identifying the publication in the public portal

If you believe that this document breaches copyright please contact us providing details, and we will remove access to the work immediately and investigate your claim 


\title{
Gaussian Filtering with Tapered Liquid Crystal Photonic Bandgap Fibers
}

\author{
L. Scolari, T. T. Alkeskjold and A. Bjarklev \\ COM DTU Department of Communications, Optics and Materials, \\ Technical University of Denmark, DK-2800 Kgs. Lyngby, Denmark

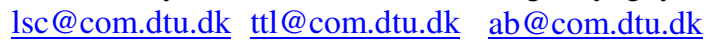

\begin{abstract}
We present a device based on a tapered Liquid Crystal Photonic Bandgap Fiber that allows active all-in-fiber filtering. The resulting Photonic Bandgap Fiber device provides a Gaussian filter covering the wavelength range $1200-1600 \mathrm{~nm}$.
\end{abstract}

\section{INTRODUCTION}

Photonic crystal fibers (PCFs) are microstructured waveguides with a large number of air holes running in the length direction of the fiber and usually located in the cladding region. An appropriately designed PCF allows light to be guided by so called modified Total Internal Reflection (m-TIR) or by the Photonic Bandgap (PBG) effect [1,2]. Optical properties of these fibers may be manipulated by filling the air holes with liquid materials. In [3,4] a device with tunable transmission properties was demonstrated by filling the air holes with polymers and with a high-index liquid, respectively. In [5] for the first time, it was shown that Liquid Crystal (LC) filled PCFs may form tunable photonic bandgap waveguides. Tunability has been achieved by exploiting both the thermo-optic effect [5] and the electro-optic effect to induce index changes to the LC [6,7]. In order to manipulate the optical properties of PCFs, a tapering technique may also be used [8]. Here, we present a device based on a tapered PCF with holes infiltrated with LC that allows shaping of the transmission spectrum. A Gaussian filter working in the range $1200-1600 \mathrm{~nm}$ is demonstrated, with possible applications in the field of optical coherence tomography (OCT), where the ideal spectrum would have a Gaussian spectral shape [9], Raman spectroscopy or fluorescence spectroscopy.

\section{PRINCIPLE OF OPERATION}

The fiber used in the experiment is a 'Large Mode Area' PCF with a solid silica core surrounded by 7 rings of air holes arranged in a triangular lattice, as shown in the inset of figure 1. The hole diameter $(d)$ is $3.3 \mathrm{~m}$, the inter-hole distance ( ) is 7.2 $\mathrm{m}$ and the fiber diameter $(D)$ is $125 \mathrm{~m}$. This fiber guides light by the principle of m-TIR. The PCF is tapered down to $100 \mathrm{~m}$ and then up again. The total length of the taper is $1.4 \mathrm{~cm}$. This length is filled with a nematic LC (Merck, Darmstadt, Germany, E7) as shown in figure 1. The ordinary and extraordinary refractive indices of this LC are $n_{o}=1.52$ and $n_{e}=1.75$ respectively, both measured at $=589.3 \mathrm{~nm}$ and its alignment is planar, with the director parallel to the fiber axis.

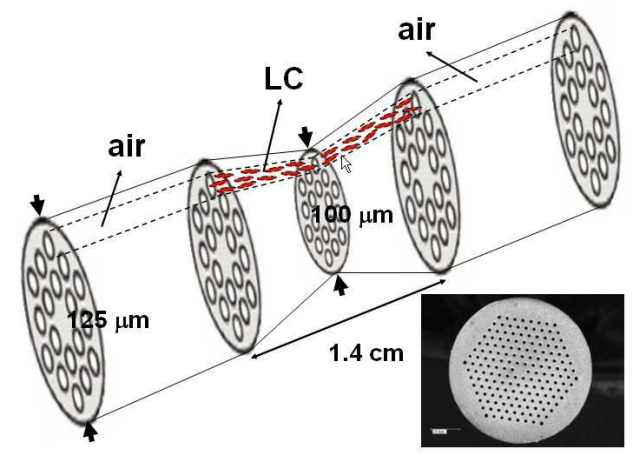

Fig.1 Schematic illustration of a tapered PCF filled with LC. All the holes are filled along the tapered section but here only the inner part of one of them is shown. Inset shows the micrograph of the end facet of the PCF used in the experiment.

The infiltration of the air holes with the LC changes the waveguiding properties of the infiltrated section, since the refractive index of the core is lower than that of the encircling cladding. The m-TIR based guidance is not possible and the section in which the LC is infiltrated can support only a number of guided wavelength bands due to the anti-resonant reflection (bandgaps) from the LC filled holes. In the isotropic case, a simple cut-off model [10] can be used to determine the wavelengths at which there are transmission minima:

$$
{ }_{m}=\frac{2 d}{m+1 / 2} \sqrt{n_{2}^{2} n_{1}^{2}}
$$

where $m$ is an integer, $d$ is the hole size, $n_{2}$ the isotropic refractive index of high-index inclusions and $n_{l}$ the refractive 
index of the background. The black line in figure 2 shows the bandgaps for an untapered PCF filled with LC. If the section that will be filled with LC is tapered before infiltrating the LC into the holes, then it is possible to further shape the transmission spectrum. In fact, the structure is scaled down along the taper and, therefore, the bandgaps move toward shorter wavelengths along the down taper length, going back to the previous position along the up taper length. Formula (1), in which the value of $\mathrm{n}_{2}$ and $n_{1}$ are taken at $1300 \mathrm{~nm}$, gives an estimated shift of $200 \mathrm{~nm}$ toward shorter wavelengths, when the fiber is tapered down at $100 \mathrm{~m}$. Only those wavelengths, which are in the bandgaps of both the untapered fiber and the tapered fiber, are guided through the taper. As shown in figure 2, the bandgap in the range 1300$1750 \mathrm{~nm}$ is expected to change its wavelength range and its shape. Its peak should shift about $100 \mathrm{~nm}$ with respect to the central wavelength of the bandgap of the untapered section. A small residual of the bandgap in the range 900-1130nm is also expected from the theory, while the other bandgaps are not expected to be seen after the taper, since they are narrow and they should be removed by the taper.

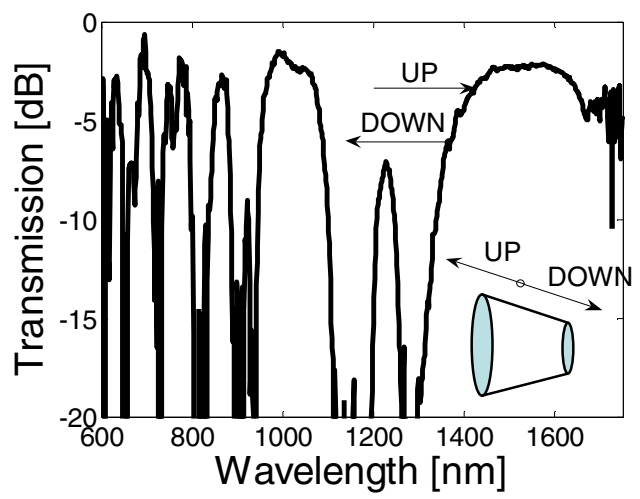

Fig.2 Transmission spectrum obtained by filling $1 \mathrm{~cm}$ section of an untapered PCF with LC. The bandgaps shift toward shorter wavelengths along the down taper length and they go back to the previous position along the up taper length.

\section{RESULTS AND DISCUSSIONS}

White light has been coupled to one end of the tapered LCPCF and the transmission spectrum has been measured by collecting the light in an optical spectrum analyzer. Figure 3 shows the resulting transmission spectrum in the range 700-1700 $\mathrm{nm}$. The peak of the Gaussian-like spectrum is at $1400 \mathrm{~nm}$, shifted about $100 \mathrm{~nm}$ with respect to the central wavelength of the bandgap of the untapered fiber, as expected. The other bandgaps are completely removed by the taper, except the remains of the bandgap in the range $900-1130 \mathrm{~nm}$, as expected by the theory. This residual bandgap can be observed in Figure 3 at $910 \mathrm{~nm}$. The Gaussian filter bandwidth is $180 \mathrm{~nm}$. The filter can be made narrower by using a smaller taper waist in order to produce a larger shift of the bandgaps.

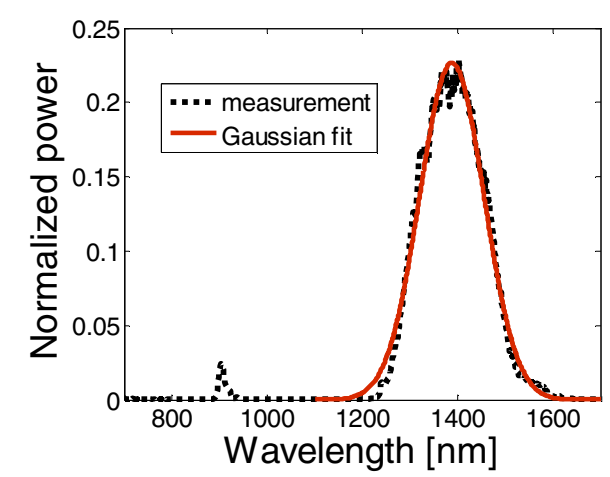

Fig.3 Measured transmission spectrum of a tapered LMA-10 filled with E7. The Gaussian fitting the spectrum is $0.2265 e^{\left(\frac{x 1388}{95.35}\right)^{2}}$

\section{CONCLUSION}

A Gaussian filter in the range 1200-1600nm has been fabricated by using a tapered PCF filled with LC. Tunability of the filter can be achieved by changing the temperature and this will be done in future investigations. The possibility of shaping the spectrum and of actively tuning it opens up the potential of using this kind of filter in applications in which all-in fiber active filtering is required. Gaussian filters can be used in the field of optical coherence tomography, while narrow filters can be used, for example, in Raman spectroscopy or fluorescence spectroscopy.

\section{REFERENCES}

[1] P. Russell, "Photonic crystal fibers," Science 299, 358-362 (2003)

[2] J.C. Knight, J. Broeng, T.A. Birks, P.St.J. Russell, "Photonic band gap guidance in optical fibers," Science 283, 1476-1478 (1998)

[3] P.S. Westbrook, B.J. Eggleton, R.S. Windeler, A. Hale, T.A. Strasser, G.L. Burdge, "Cladding-mode resonances in hybrid polymer-silica microstructured optical fiber gratings, " Photonics Tech. Lett, 12, 495-497 (2000)

[4] R.T. Bise, R.S. Windeler, K.S. Kranz, C. Kerbage, B.J. Eggleton, D.J. Trevor, "Tunable photonic band gap fiber," Optical Fiber Communication Conference Technical Digest Washington, DC, 466-468, 2002

[5] T.T. Larsen, A. Bjarklev, D.S. Hermann, J. Broeng, "Optical devices based on liquid crystal photonic bandgap fibers," Opt. Express 11, 2589-2596 (2003)

[6] M.W. Haakestad, T.T. Alkeskjold, M.D. Nielsen, L. Scolari, J. Riishede, H.E. Engan, A. Bjarklev, "Electrically Tunable Photonic Bandgap Guidance in a Liquid Crystal Filled Photonic Crystal Fiber," IEEE Phot. Tech. Lett. 17, 819-821 (2005)

[7] L. Scolari, T.T. Alkeskjold, J. Riishede, A. Bjarklev, D. Hermann, A. Anawati, M. Nielsen, P. Bassi, "Continuously tunable devices based on electrical control of dual-frequency liquid crystal filled photonic bandgap fibers, " Opt. Express 13, 7483-7496 (2005)

[8] H.C. Nguyen, B.T. Kuhlmey, E.C. Mägi, M.J. Steel, P. Domachuk, C.L. Smith, B.J. Eggleton, "Tapered photonic crystal fibers: properties, characterization and applications," Appl. Phys. B 81, 377-387 (2005)

[9] W. Drexler, "Ultrahigh-resolution optical coherence tomography," Journal of Biomedical Optics 9, 47-74 (2004)

[10] N.M. Litchinitser, S.C. Dunn, P.E. Steinvurzel, B.J. Eggleton, T.P. White, R.C. McPhedran, C.M. de Sterke, "Application of an ARROW model for designing tunable photonic devices," Opt. Express 12, 1540-1550 (2004) 